\title{
BMJ Open Predictors of health-related quality of life among patients with diabetes on follow-up at Nekemte specialised Hospital, Western Ethiopia: a cross- sectional study
}

\author{
Bikila Regassa Feyisa (D), Mekdes Tigistu Yilma, Belachew Etana Tolessa
}

To cite: Feyisa BR, Yilma MT, Tolessa BE. Predictors of health-related quality of life among patients with diabetes on follow-up at Nekemte specialised Hospital, Western Ethiopia: a crosssectional study. BMJ Open 2020;10:e036106. doi:10.1136/ bmjopen-2019-036106

- Prepublication history and additional material for this paper are available online. To view these files, please visit the journal online (http://dx.doi. org/10.1136/bmjopen-2019036106).

Received 30 November 2019 Revised 01 June 2020 Accepted 18 June 2020

Check for updates

(C) Author(s) (or their employer(s)) 2020. Re-use permitted under CC BY-NC. No commercial re-use. See rights and permissions. Published by BMJ.

Department of Public Health, Institute of Health Sciences, Wollega University, Nekemte, Oromia, Ethiopia

Correspondence to Bikila Regassa Feyisa; bikregasa@gmail.com

\section{ABSTRACT}

Objective To assess health-related quality of life ( $\mathrm{HRQOL}$ ) and its predictors among patients with diabetes on followup at Nekemte Specialised Hospital in Western Ethiopia. Design, setting and participants This facility-based cross sectional study was conducted among 224 patients with diabetes mellitus (types I and II) on follow-up at one of the public hospitals in western Ethiopia. Respondents were selected by systematic random sampling and interviewed with the aid of a questionnaire.

Main outcome measured HRQOL was measured by using the Medical outcomes study 36-item Short Form (SF-36) Health Survey from 15 April to 5 June 2019. A structured questionnaire was used for data collection from participants selected by systematic random sampling. Multiple linear regression was used for the final model. Result A total of 215 patients with diabetes consented and completed the study, giving a response rate of $96 \%$. The mean score of the overall HRQoL of the study participants was $50.3 \pm 18.1$. The highest mean score was obtained in the physical functioning domain and the lowest mean score in the general health domain. Age, education status, history of smoking, feeling of stigmatisation and body mass index were inversely associated with the overall HRQoL. Gender (male), marital status (currently married), absence of comorbidity and absence of chronic complications related to diabetes mellitus were positively associated with overall HRQoL.

Conclusion The overall HRQoL of patients with diabetes on follow-up at the study area was found to be moderate. General health, mental health, bodily pain and vitality were the most affected domains. Both the mental and physical components need to be considered when caring for the patients with diabetes on follow-up beyond provision of treatment.

\section{INTRODUCTION}

Diabetes mellitus (DM) refers to a group of common metabolic disorders that share the phenotype of hyperglycaemic. Several distinct types of DM exist and are caused by complex interactions of genetics and environmental factors. The two broad categories of DM are

\section{Strengths and limitations of this study}

- To the best of the authors' knowledge, the study was the first to explore the predictors of health-related quality of life among patients with types 1 and 2 diabetes mellitus in Ethiopia.

- We used an established tool with good psychometric properties.

- No comparison was made between types 1 and 2 diabetes mellitus.

- The study had a cross-sectional design that could make it difficult to identify whether cause or effect happened first.

designated as type 1 and type 2 DM. It is characterised by chronic high blood glucose level (>126 mg/dL for fasting blood sugar and/or a 2-hour postprandial glucose of $\geq 200 \mathrm{mg} / \mathrm{dL}$ or if the individual had symptoms of diabetes and a random plasma glucose $\geq 200 \mathrm{mg} / \mathrm{dL}$ (confirmed by repeat testing). ${ }^{1-3}$

$\mathrm{DM}$ is becoming a growing problem that has significant impact on health status and quality of life. It is considered an urgent public health problem, which can influence the health-related quality of life (HRQoL) negatively. ${ }^{2}{ }^{3}$ Worldwide, $8.8 \%$ of adults aged 20-79 years had diabetes in 2015 which was projected to reach 366 million in 2030 and 642 million ( 1 in 10 adults) by 2040, among which about $75 \%$ lived in low-income and middle-income countries. Globally about 5 million deaths among those aged 20-99 years were attributable to diabetes. ${ }^{4-7}$ There is now a consensus that the health of the general population cannot be well characterised from the analyses of mortality and morbidity statistics alone and that there is also a need to consider health in terms of people's assessment of their sense of well-being and ability to perform social roles. ${ }^{7-9}$ 
HRQoL is a multidimensional concept that focuses on the impact of illness and treatment on patients, and it can measure patients' perceptions of illness and treatment, their perceived needs for healthcare providers and their preferences for treatment and outcomes of the disease. ${ }^{10}$ It concerns both subjective and objective measurements of individuals. It has been defined as an overall general well-being that comprises objective descriptors and subjective evaluations of physical, material, social and emotional well-being together with the extent of personal development and purposeful activity, all weighted by a personal set of values. ${ }^{11}$

DM negatively influences HRQoL. This negative influence affects many aspects of a person's life, including the psychological impact of being chronically ill, dietary restrictions, changes in social life, symptoms of an inadequate metabolic system, chronic complications and in due course lifelong infirmities. ${ }^{12-15}$ Studies have indicated that the HRQoL of patients with DM is decreased by different domains of HRQoL such as role limitation due to the disease, emotional disturbances, pain and fatigability. Other factors related to HRQoL among patients with diabetes also affect both quality and length of life of patients with DM. These are sociodemographics and economic status, behavioural, clinical and social-related factors. ${ }^{16}{ }^{17} \mathrm{DM}$ permanently changes the patient's lifestyle. Daily self-care, consisting of daily insulin injections or oral anti diabetic agents, self-monitoring of blood glucose and diabetic recommended diet has an impact on HRQoL. Moreover, the acute and chronic complications which might develop in due course affect the patients' HRQoL. ${ }^{18} 19$

In Ethiopia, even though programmes have been launched regarding chronic disease management, prevention, screening, diagnosis, treatment and care, little is emphasised on factors that affect the HRQoL among patients. The Ethiopian National Guideline on major non-communicable diseases lacks the specific areas of HRQoL dimension which is affected by the disease. The existing articles and reviews have tried to indicate the epidemiology, complications, therapies, comparisons of treatments and health strategies but the data regarding predictors of HRQoL and how much it is actually affected by the condition is scarce. ${ }^{20}$ Therefore, the study was designed to predict the level of HRQoL and factors associated with it among patients with diabetes in Nekemte Specialised Hospital (NSH).

\section{RESEARCH DESIGN AND METHOD \\ Study design and setting}

Facility-based cross-sectional study design was employed from 15 April to 5 June 2019. The study was conducted among patients with diabetes on follow-up at NSH which is found in Nekemte City located in Western Ethiopia and $331 \mathrm{~km}$ away from the capital city of Ethiopia, Addis Ababa.
Diabetic follow-up and care services started separately as chronic diseases clinic at the Hospital in 2010 with 96 cases. According to the unpublished report of NSH on the 1 February 2019, 591 patients with diabetes of both types 1 and 2 were on follow-up at the chronic disease clinic.

\section{Eligibility criteria}

All known patients with DM of type 1 and type 2 who have been on follow-up for at least 1-year duration and age greater than 18 years at NSH were included while patients with diabetes of both types who could not respond to the interview because of very serious illness were excluded from the study.

\section{Sample size and sampling procedure}

The sample size was determined assuming normally distributed independent means. The overall mean score of 52.6 \pm 12.1 obtained from a study on HRQoL of patients with diagnosed type 2 diabetes in Ethiopia ${ }^{21}$ was used to calculate the sample size for the first objective. Sample size for the second objective was calculated using the mean of the independent variables from different studies. The calculated sample sizes were compared for the maximum value with assumption of $95 \% \mathrm{CI}(\mathrm{Z} \alpha / 2=1.96)$ and $5 \%$ marginal error. After using correction formula and adding $5 \%$ non-response rate, the final sample size became 224 .

Systematic random sampling was used to select the study participants. The sampling interval was calculated by dividing the total number of patients with diabetes on follow-up as counted from the registries by the calculated sample size.

\section{Data collection procedure}

Data were collected using an interviewer-administered structured questionnaire which was adopted from the Medical Outcomes Study (MOS) 36-item SF-36 health survey. The English version of the questionnaire was translated to Afaan Oromoo (the local language) and translated back to English by other language experts to check its consistency. We recruited and trained four BSc nurse data collectors and one experienced MPH professional supervisor for the data collection process.

\section{Instruments}

The instrument consists of the WHO SF-36 item questionnaires adopted from MOS 36-SF instrument ${ }^{22}$ and sociodemographic and economic profiles. The SF-36 consists of 36 questions containing physical functioning (10 items), role limitation due to physical health (4 items), body pain ( 2 items), vitality ( 4 items), social functioning (2 items), role limitation due to emotional problem (3 items), mental health (5 items) and general health (6 items).

\section{Data processing analysis}

Each item of SF-36 was scored on a linear scale and the negatively worded questions were inversely coded before 
analysis. The score of each domain was obtained by summation of the corresponding items. The scores were then linearly transformed on a 0-100 scale. Mean scores were then adjusted to make the domain scores comparable with the scores used in the MOS (0-100) (lower scores denote lower quality of life).

Aggregate component scores were calculated by principal component analysis (PCA) after all eight domain scores were checked. All assumptions were checked prior to running PCA. Components with eigen value greater than 1 were retained for further analysis. The factor loadings above 0.4 were taken and included in the result. The retained factors were orthogonally rotated. Finally, two summary scores (subscales), Physical Component Score and Mental Component Score (MCS), were derived from PCA.

Dummy variables were created for categorical variables that have more than two categories like marital status, educational status, age category and the drug regimen.

For the internal consistency reliability of the SF-36 items, Cronbach's alpha ${ }^{23}$ was checked and found to be 0.876 which was in the acceptable level.

Betas ( $\beta$-Coefficients) were used to interpret the strength of predictors of HRQoL. The degree of association between pairs of variables was measured by Pearson's correlation coefficient $(r)$. The independent variables at $\mathrm{p}<0.05$ were considered as statistically significant. Multicollinearity was checked using variance inflation factors (VIFs). The maximum value for VIF was 2.3.

\section{Patient and public involvement}

No patients nor the public were involved in the design, analysis and interpretation of this study and will not be involved in the dissemination of the results.

\section{RESULTS \\ Sociodemographic characteristics}

A total of 215 patients with diabetes on follow-up at NSH were included in the analysis with response rate of $96 \%$. Among the total respondents, $122(56.7 \%)$ of them were males and the mean age of all the respondents was $41.6 \pm 15.4$ years, $141(65.6 \%)$ of them were resident in the urban area. More than two-thirds, $146(67.9 \%)$ of the total respondents were married and majority, 198 $(92.1 \%)$ of them were Oromo. The mean family size of the respondents was $4.8 \pm 1.5$. Thirty-eight $(17.7 \%)$ of the study participants could not read and write and only 52 $(24.2 \%)$ of them were employed either at government and/or non-governmental organisations (table 1).

\section{Medical history and health condition}

More than half, 125 (58.1\%) of the study participants had type 2 DM. Almost half, 108 (50.2\%) of them had been diagnosed within the last 5 years. Regarding treatment, 99 $(46.0 \%)$ of the patients were using only insulin while 93 $(43.3 \%)$ and $23(10.7 \%)$ were using oral hypoglycaemic
Table 1 Sociodemographic and socioeconomic characteristics of patients with diabetes on follow-up at $\mathrm{NSH}$, Nekemte, East Wollega, West Ethiopia, $(n=215)$

\begin{tabular}{|c|c|c|}
\hline Variables & Frequency $(n=215)$ & Percentage \\
\hline \multicolumn{3}{|l|}{ Sex } \\
\hline Male & 122 & 56.7 \\
\hline Female & 93 & 43.3 \\
\hline Mean age in year & 41.6ะSD 15.4 & \\
\hline \multicolumn{3}{|l|}{ Residence } \\
\hline Urban & 141 & 65.6 \\
\hline Rural & 74 & 34.4 \\
\hline \multicolumn{3}{|l|}{ Marital status } \\
\hline Married & 146 & 67.9 \\
\hline Single & 42 & 19.5 \\
\hline Divorced & 6 & 2.8 \\
\hline Widowed & 21 & 9.8 \\
\hline \multicolumn{3}{|l|}{ Ethnicity } \\
\hline Oromo & 198 & 92.1 \\
\hline Amhara & 9 & 4.2 \\
\hline Guraghe & 5 & 2.3 \\
\hline Other* & 3 & 1.4 \\
\hline \multicolumn{3}{|l|}{ Educational status } \\
\hline Cannot read and write & 38 & 17.7 \\
\hline Grades 1-8 & 63 & 29.3 \\
\hline Grades 9-12 & 50 & 23.3 \\
\hline College/university & 64 & 29.8 \\
\hline \multicolumn{3}{|l|}{ Occupation } \\
\hline $\begin{array}{l}\text { Government/NGO } \\
\text { employee }\end{array}$ & 52 & 24.2 \\
\hline Merchant & 23 & 10.7 \\
\hline Farmer & 41 & 19.1 \\
\hline Housewife & 46 & 21.4 \\
\hline Retired & 23 & 10.7 \\
\hline Other† & 30 & 14.0 \\
\hline \multicolumn{3}{|c|}{ Economic status (Wealth index) } \\
\hline Poorest & 43 & 20.0 \\
\hline Poor & 38 & 17.7 \\
\hline Medium & 46 & 21.4 \\
\hline Wealthy & 45 & 20.9 \\
\hline Wealthiest & 43 & 20.0 \\
\hline
\end{tabular}

${ }^{*}$ Other (tigre, silte).

†Other (student, carpenter).

NGO, non-governmental organisation; NSH, Nekemte Specialised Hospital.

agents and both insulin and oral hypoglycaemic agents, respectively.

Nearly half, 103 (47.9\%) of the study participants were co morbid and hypertension accounted for 85 (82.5\%) of comorbid conditions. Sixty-three $(29.3 \%)$ of the study 
Table 2 Medical history and health condition of patients with diabetes on follow-up at NSH, Nekemte, East Wollega, West Ethiopia, $(n=215)$

\begin{tabular}{|c|c|c|}
\hline Variable & Frequency (n) & Percent (\%) \\
\hline \multicolumn{3}{|l|}{ Duration of DM (years) } \\
\hline$<5$ & 108 & 50.2 \\
\hline $6-10$ & 59 & 27.4 \\
\hline $11-15$ & 32 & 14.9 \\
\hline$>15$ & 16 & 7.4 \\
\hline \multicolumn{3}{|l|}{ Drug regimen } \\
\hline Insulin only & 99 & 46.0 \\
\hline Oral hypoglycaemic agents & 93 & 43.3 \\
\hline $\begin{array}{l}\text { Insulin and oral } \\
\text { hypoglycaemic agents }\end{array}$ & 23 & 10.7 \\
\hline \multicolumn{3}{|l|}{ Presence of comorbidity } \\
\hline Yes & 103 & 47.9 \\
\hline No & 112 & 52.1 \\
\hline \multicolumn{3}{|c|}{ Presence of diabetic-related chronic complication } \\
\hline Yes & 69 & 32.1 \\
\hline No & 146 & 67.9 \\
\hline \multicolumn{3}{|l|}{ Types of acute complications } \\
\hline DKA & 40 & 63.5 \\
\hline Hypoglycaemic & 20 & 31.7 \\
\hline $\begin{array}{l}\text { Non-ketotic hyperosmolar } \\
\text { state }\end{array}$ & 3 & 4.8 \\
\hline \multicolumn{3}{|l|}{ Type of chronic complication } \\
\hline Diabetic neuropathy & 34 & 49.3 \\
\hline Diabetic retinopathy & 19 & 27.5 \\
\hline Diabetic nephropathy & 14 & 20.3 \\
\hline Other & 2 & 2.9 \\
\hline \multicolumn{3}{|l|}{ Body mass index $\left(\mathrm{kg} / \mathrm{m}^{2}\right)$} \\
\hline$<18.5$ & 5 & 2.3 \\
\hline $18.5-25$ & 122 & 56.7 \\
\hline $25-30$ & 80 & 37.2 \\
\hline$>30$ & 8 & 3.7 \\
\hline
\end{tabular}

DKA, diabetes keto acidosis; DM, diabetes mellitus; NSH, Nekemte Specialised Hospital.

participants had diabetes-related acute complications which included diabetes keto acidosis, 40 (63.5\%), hypoglycaemic $20(31.7 \%)$ and non-ketotic hyperosmolar state $3(4.8 \%)$ respectively. Sixty-nine of the study subjects had diabetes-related chronic complications which accounted for around $32.1 \%$ where diabetic neuropathy (including foot ulcer, peripheral pain and gangrene) covered almost half, $49.3 \%$ as illustrated in table 2 .

\section{HRQOL of the study participants}

The transformed mean score of the overall HRQoL of the study participants was found to be $50.3 \pm 18.1$ with minimum and maximum scores of 16.4 and 79.1 , respectively. Among the eight domains of HRQoL, the study participants scored highest $(63.2 \pm 34.4)$ mean score in physical functioning and lowest $(30.2 \pm 22.9)$ mean score in general health domain. When analysing the HRQoL by domains general health, mental health, bodily pain and vitality had mean score below 50 indicating that they were the most affected domains among the patients with diabetes (table 3 ).

Two component scores of the HRQoL were generated by PCA with the total variance explained $66.8 \%$. Physical functioning, physical role limitation, general health and bodily pain dimension scales correlate most highly with the physical component of HRQoL. Moreover, the mental health component of HRQoL correlates most highly with mental health, social functioning, emotional role limitation and vitality (online supplementary annex 1 and 2). The higher mean score was found for the MCS $(51.8 \pm 16.7)$ with the maximum score of 80.8 .

\section{Predictors of HRQoL of life of patients with diabetes}

The multiple linear regression model indicated that a unit increase in age would likely decrease HRQoL of patients with diabetes by 0.25 ( $\beta=-0.25,95 \%$ CI -0.43 to -0.07 , $\mathrm{p}=0.007$ ) controlling all other independent variables.

Males had about five times better HRQoL when compared with females $(\beta=5.23$, 95\% CI 1.10 to 9.36, $\mathrm{p}=0.013$ ). Respondents who were married had about five times better HRQoL compared with those who were single controlling for all other independent variables $(\beta=5.30,95 \%$ CI 1.88 to 10.52 . $p=0.04)$.

Respondents who were unable to read and write had about nine times lower HRQoL ( $\beta=-8.81,95 \%$ CI -14.88 to $-2.82, \mathrm{p}=0.004)$ when compared with those who achieved college and above after controlling all other predictors.

History of smoking was found to affect the HRQoL status of the patients with diabetes. Patients with diabetes who had history of smoking had nine units times lower HRQoL ( $\beta=-9.03,95 \%$ CI -15.23 to $-4.69, \mathrm{p}<0.001)$ when compared with their counterparts. Similarly, feelings of stigmatisation because of being a patient with diabetes would likely decrease HRQoL by 5.25 units $(\beta=-5.25$, $95 \% \mathrm{CI}-8.94$ to $-1.56, \mathrm{p}=0.005$ ) compared with their counterparts.

Absence of comorbid conditions and chronic complications related to DM was found to increase HRQoL. In both cases, those who had not had the condition had about six units better HRQoL than their counterparts. A one-unit increase in the body mass index (BMI) would likely decrease the HRQoL by 3.56 units $(\beta=-3.56,95 \%$ CI -6.94 to $-0.18, \mathrm{p}=0.040$ ) table 4 .

\section{DISCUSSION}

The current study assessed the overall HRQoL among patients with type 1 and type $2 \mathrm{DM}$ and its predictors in NSH. 
Table 3 HRQoL of patients with diabetes at NSH, East Wollega, West Ethiopia, $(n=215)$

\begin{tabular}{|c|c|c|c|c|}
\hline Domains of HRQoL, overall HRQoL, PCS and MCS & Mean & SD & Minimum score (\%) & Maximum score (\%) \\
\hline Physical functioning & 63.2 & 34.4 & 14.4 & 97.6 \\
\hline Role limitation due to physical health & 53.4 & 44.8 & 8.6 & 98.2 \\
\hline Role limitation due to emotional problem & 52.77 & 45.8 & 6.97 & 98.6 \\
\hline Energy/fatigue (vitality) & 48.5 & 7.8 & 20.0 & 75.0 \\
\hline Emotional well-being (mental health) & 49.8 & 8.0 & 20.0 & 72.0 \\
\hline Social functioning & 56.0 & 30.1 & 12.9 & 86.0 \\
\hline Bodily pain & 48.6 & 11.0 & 12.5 & 80.0 \\
\hline General health & 30.2 & 22.9 & 7.3 & 95.0 \\
\hline Overall HRQoL & 50.3 & 18.1 & 16.4 & 79.1 \\
\hline PCS & 48.8 & 21.9 & 10.0 & 87.5 \\
\hline MCS & 51.8 & 16.7 & 19.8 & 80.8 \\
\hline
\end{tabular}

HRQoL, health-related quality of life; MCS, Mental Component Score; NSH, Nekemte Specialised Hospital; PCS, Physical Component Score.

According to this finding, the transformed overall mean score of the HRQoL was found to be moderate. The highest mean score was recorded in the physical functioning domain. Domains of general health, mental health, bodily pain and vitality had mean score below the average. This was lower when compared with the results obtained in other places. ${ }^{12} 1424$ This discrepancy might be due to the differences in the socioeconomic status of the patients and cultural differences across different regions. But it was congruent with the study result from Felege Hiwot Referral Hospital; Ethiopia. ${ }^{21}$ This might be because of the possible similarity of the socioeconomic status of the study areas where the study participants shared almost the same lifestyle and cultural perspectives.

The PCS and MCS mean scores from the current study were comparable with other studies. ${ }^{13}{ }^{25}$ However, another study from Tehran hospital ${ }^{26}$ indicated that the PCS and MCS mean score was relatively higher than that of the present study. The possible explanation for this difference could be the cultural and sociodemographic difference of the patients across different study areas. The subjective nature of the HRQoL and the component measurement across different patients might also explain the differences as HRQoL concerns subjective evaluations and also objective descriptors. ${ }^{10} 11$

In this study sex, age, marital status, educational level were among the sociodemographic factors that had significant association with the HRQoL of patients with DM. For instance, inability to read and write was inversely associated with the HRQoL indicating that patients with diabetes who cannot read and write have lower understanding about the disease, complications and treatment as well as being unable to make decisions on better selfcare. The study disagreed with the study result from Greece where sex and educational level had not significant association with HRQoL. ${ }^{10}$ This difference could be because of the difference in sociodemographic status of the patients.
As age increases the HRQoL of the patients with diabetes decreased. This result was also noted in similar studies. ${ }^{11} 1327$ This might be because of the physiological alteration of the patients as they got older. Older individuals are mostly limited in physical activities, coping with pain intensity and relief from pain. ${ }^{26}$ However, findings from other parts of Ethiopia, South Africa and the Nordic countries were inconsistent with the current study result where age has no association with HRQoL. ${ }^{21} 2829$

Married patients with diabetes had higher HRQoL when compared with the single patients. The findings from other parts of Ethiopia also agreed with the current study result. ${ }^{21}{ }^{30}$ The possible explanation for this could be that the married patients might be psychologically stable and have better social interaction in relation to those who are single.

Male patients with diabetes had higher HRQoL mean score when compared with the female patients with the highest domain score of physical functioning and lower in general health in both sexes. This goes in line with other literatures which indicated that women had worse HRQoL than males. ${ }^{11} 31$ But it contradicted with other studies. ${ }^{122730}$ This discrepancy could be due to the gender impact as most of the time women are treated inferiorly. They are less autonomous in giving decision on behalf of their rights. Moreover, evidences showed that women were more likely affected by DM than males. The risk of central obesity is higher among women which in turn lead to the enhancement of the risk of complication of DM. This greatly reduces HRQoL of the clients. ${ }^{1}$

Although occupation and economic status of patients with DM seems to affect HRQoL, the current study did not show significant association with HRQoL of patients with diabetes. However, there were other studies showing significant associations between HRQoL and the patients' occupational and economic status. ${ }^{12}{ }^{21}$ The discrepancy could be due to the methodological differences. In the studies, economic status was reported just from the 
Table 4 Multiple linear regression analysis of patients with diabetes on follow-up at NSH, East Wollega, West Ethiopia, $(n=215)$

\begin{tabular}{|c|c|c|c|c|c|c|}
\hline \multirow[b]{2}{*}{ Variables } & \multicolumn{2}{|c|}{ Unstandardised coefficient } & \multirow{2}{*}{$\begin{array}{l}\text { Standardised } \\
\text { coefficient } \\
\beta\end{array}$} & \multicolumn{2}{|l|}{$95 \% \mathrm{Cl}$} & \multirow[b]{2}{*}{$P$ value } \\
\hline & $\beta$ & SE & & Lower & Upper & \\
\hline (Constant) & 69.41 & 10.31 & & 49.16 & 89.74 & $0.00^{\star \star \star}$ \\
\hline \multicolumn{7}{|l|}{ Sex } \\
\hline Female & 1 & 1 & 1 & 1 & 1 & 1 \\
\hline Male & 5.23 & 2.11 & 0.14 & 1.10 & 9.36 & $0.013^{*}$ \\
\hline Age & -0.25 & 0.08 & -0.20 & -0.43 & -0.07 & $0.007^{*}$ \\
\hline \multicolumn{7}{|l|}{ Marital status } \\
\hline Single & 1 & 1 & 1 & 1 & 1 & 1 \\
\hline Married & 5.30 & 2.69 & 0.11 & 1.88 & 10.52 & $0.04^{*}$ \\
\hline Divorced & -4.60 & 5.26 & -0.04 & -14.98 & 5.78 & 0.38 \\
\hline Widowed & -4.07 & 3.42 & -0.07 & -10.81 & 2.67 & 0.24 \\
\hline \multicolumn{7}{|l|}{ Educational status } \\
\hline Cannot read and write & -8.81 & 3.06 & -0.19 & -14.88 & -2.82 & $0.004^{\star}$ \\
\hline Grade 1-8 & -2.94 & 2.49 & -0.07 & -7.84 & 1.97 & 0.24 \\
\hline Grade 9-12 & 0.04 & 2.62 & 0.001 & -5.13 & 5.22 & 0.98 \\
\hline College and above & 1 & 1 & 1 & 1 & 1 & 1 \\
\hline \multicolumn{7}{|l|}{ Smoking history } \\
\hline Yes & -9.03 & 2.66 & -0.21 & -15.23 & -4.69 & $0.001^{* *}$ \\
\hline No & 1 & 1 & 1 & 1 & 1 & 1 \\
\hline \multicolumn{7}{|l|}{ Feeling of stigmatised } \\
\hline Yes & -5.25 & 1.89 & -0.15 & -8.94 & -1.56 & $0.005^{*}$ \\
\hline No & 1 & 1 & 1 & 1 & 1 & 1 \\
\hline \multicolumn{7}{|l|}{ Comorbidity status } \\
\hline Yes & 1 & 1 & 1 & 1 & 1 & 1 \\
\hline No & 6.05 & 2.18 & 0.16 & 1.78 & 10.33 & $0.006^{*}$ \\
\hline \multicolumn{7}{|l|}{ Chronic complication status } \\
\hline Yes & 1 & 1 & 1 & 1 & 1 & 1 \\
\hline No & 6.04 & 2.28 & 0.11 & 1.54 & 10.53 & $0.009^{*}$ \\
\hline BMI & -3.56 & 1.71 & -0.12 & -6.94 & -0.18 & $0.040^{*}$ \\
\hline DM duration & 0.15 & 1.10 & 0.01 & -2.02 & 2.33 & 0.89 \\
\hline \multicolumn{7}{|l|}{ Types of DM } \\
\hline Type 1 & 1 & 1 & 1 & 1 & 1 & 1 \\
\hline Type 2 & 4.45 & 2.39 & 0.12 & -0.24 & 9.17 & 0.064 \\
\hline \multicolumn{7}{|l|}{ Drug regimen } \\
\hline Insulin only & 1 & 1 & 1 & 1 & 1 & 1 \\
\hline $\begin{array}{l}\text { Oral Hypoglycemic Agents } \\
(\mathrm{OHA})\end{array}$ & -5.66 & 3.46 & -0.16 & -12.48 & 1.15 & 0.103 \\
\hline Both & -1.42 & 4.02 & -0.02 & -9.35 & 6.51 & 0.72 \\
\hline
\end{tabular}

Dependent variable: overall health related quality of life.

${ }^{*} \mathrm{p}<0.05{ }^{* *} \mathrm{p}<0.01{ }^{* * *} \mathrm{p}<0.001$

BMI, body mass index; DM, diabetes mellitus; NSH, Nekemte Specialised Hospital. 
mean annual income of the patients. However, since the patients' way of disclosing their income level might not be accurate especially for unsalaried patients. This might overestimate the association.

In this study, patients who had history of smoking had decreased HRQoL when compared with their counterparts. This result was supported by the report from CDC and a study from the USA that indicated the direct impact of smoking altering the health condition of the patients with diabetes and reduced their HRQoL. ${ }^{52}$ Smokers are more likely to have central fat accumulation than nonsmokers, and smoking is known to induce insulin resistance and compensatory insulin secretion responses, which could explain the increased risk of diabetes in those who smoke. ${ }^{22}$ But it was not associated factor in other studies. ${ }^{26} 33$ This could likely be because of difference in methodology.

Both comorbidity condition and chronic complication related to diabetic status was found to affect the HRQoL status which was similar with other studies. ${ }^{14} 15212434$ This could be due to the fact that co morbid conditions are another challenge that could put the patients in worrying conditions. Patients might seek healthcare for both or above diseases in which case they were emotionally diseased, the role due to emotional problem might be under question. All the domains of HRQoL directly or indirectly would be affected. In another way, those who developed chronic complications would also live under the double crisis. In one way, they felt unhappy of being patient with diabetes and in other way they would be under the psychological, physical, emotional, social and spiritual agony.

In this study, the increase in BMI affected HRQoL negatively. But studies from South Africa indicated that there was no significant association between BMI and HRQoL. ${ }^{13}{ }^{28}$ This discrepancy could be due to the difference in the patients with diabetes' knowledge gap and practice regarding their lifestyle modification.

Feeling of stigmatisation of being a patient with diabetes was inversely associated with HRQoL. This result goes in line with other literatures. ${ }^{17}$ Because the patients with diabetes are living under multiple restrictions, they would likely feel stigmatised in all aspects of their life. They are often restricted with regard to the amount, type and timing of food consumed. For example, eating mandatory foods at certain times, waiting for insulin to take effect before eating. These restrictions may negatively affect an individual's HRQoL and their interaction with people around them, in their social lives and in the work place.

The study had several limitations that have to be put in to consideration when used by other researchers. Since the study was a cross sectional study design, it is difficult to infer the cause-effect relationship (temporal relation). The study was facility based which could not be generalised to all patients with diabetes in the community. Face-to-face interviews were conducted by considering the different level of education of the participants, which might lead to the social desirability bias and could overestimate the result. The effect of recall bias also cannot be ruled out.

In conclusion, the present study identified that the HRQoL of patients with diabetes on follow-up at NSH was moderate. Domains of general health, mental health, bodily pain and vitality were the most affected domains among the patients with diabetes. Sex, age, education status, marital status, history of smoking status, BMI, feeling of stigma status, comorbidity status and diabeticrelated chronic complication status were predictors of HRQoL identified in this study.

There are several avenues for further research based on the current finding. Longitudinal studies with larger sample size need to be conducted in order to generalise the overall HRQoL of patients with diabetes at national level. Moreover, experimental and qualitative study design needs to be considered focusing on lifestyle modification of patients with diabetes.

Acknowledgements We are grateful to Wollega University, the study participants, data collectors and all other personnel who contribute their valuable input for the study to be accomplished.

Contributors All authors were contributed from the conception of the study to the final draft of the manuscript. Material preparation, data collection, analysis and interpretation of the result were carried out by BRF, MTY and BET. The first draft of the manuscript was written by BRF and reviewed by MTY and BET. All authors read and approved the final manuscript.

Funding This work was financially supported by Wollega University with grant number WU/RD/256/2011.

Patient and public involvement Patients and/or the public were not involved in the design, or conduct, or reporting, or dissemination plans of this research.

Patient consent for publication Not required.

Ethics approval The study received letter of approval from Research Ethics Review Committee (RERC) of Wollega University, DPH/0081/2011.

Provenance and peer review Not commissioned; externally peer reviewed.

Data availability statement Data are available on reasonable request through the email address of the corresponding author.

Open access This is an open access article distributed in accordance with the Creative Commons Attribution Non Commercial (CC BY-NC 4.0) license, which permits others to distribute, remix, adapt, build upon this work non-commercially, and license their derivative works on different terms, provided the original work is properly cited, appropriate credit is given, any changes made indicated, and the use is non-commercial. See: http://creativecommons.org/licenses/by-nc/4.0/.

ORCID iD

Bikila Regassa Feyisa http://orcid.org/0000-0002-7191-0218

\section{REFERENCES}

1 Fauci KB, Jameson HL. Harrisons's principles of internal medicine. 17th ed. McGraw-Hill's Access medicine, 2005: 2152-80.

2 American Diabetes Association. Standards of medical care for patients. Diabetes Care 2002;25:s33-49.

3 Center for disease control and prevention. National diabetes fact sheet, 2008

4 Boyle JP, Honeycutt AA, Venkat Narayan KM, et al. Projection of diabetes burden through 2050. Diabetes Care 2001;24:1936-40.

5 Center for Control and Prevention of diseases. Smoking and diabetes, 2014. Available: https://www.cdc.gov/tobacco/data statistics/sgr/50th anniversary/pdfs/fs_smoking_diabetes_508.pdf [Accessed 28 Mar 2019].

6 Bommer C, Sagalova V, Heesemann E, et al. Global economic burden of diabetes in adults: projections from 2015 to 2030. Diabetes Care 2018;41:963-70. 
7 Cho NH, Shaw JE, Karuranga S, et al. IDF diabetes atlas: global estimates of diabetes prevalence for 2017 and projections for 2045. Diabetes Res Clin Pract 2018;138:271-81.

8 Al-shehri AH, Taha AZ, Bahnassy AA, et al. Health-related quality of life in type 2 diabetic patients. Ann Saudi Med 2008;25:352-60.

9 Kebede D, Alem A, Shibre T, et al. Health related quality of life (SF36) survey in Butajira, rural Ethiopia: normative data and evaluation of reliability and validity. Ethiop Med J 2004;42:289-97.

10 Dinesh Khanna JT. Health-related quality of Life- an introduction. Am J Manag Care 2007;13:218-23.

11 Goli M, Salarvand S, Dehvan F, et al. Health-related quality of life in Iranian patients with Thalassemia major : a systematic review and meta-analysis. Int J Pediatr 2018;6:8483-94.

12 Sreedevi A, Cherkil S, Kuttikattu DS, et al. Validation of WHOQOLBREF in Malayalam and determinants of quality of life among people with type 2 diabetes in Kerala, India. Asia Pac J Public Health 2016;28:62S-9.

13 Papazafiropoulou AK, Bakomitrou F, Trikallinou A, et al. Diabetesdependent quality of life (ADDQOL) and affecting factors in patients with diabetes mellitus type 2 in Greece. BioMed Central 2018;10:4-9.

14 Al Hayek AA, Robert AA, Al Saeed A, et al. Factors associated with health-related quality of life among Saudi patients with type 2 diabetes mellitus: a cross-sectional survey. Diabetes Metab J 2014;38:220-9.

15 Anderson BJ, Laffel LM, Domenger C, et al. Factors associated with diabetes-specific health-related quality of life in youth with type 1 diabetes: the global teens study. Diabetes Care 2017;40:1002-9.

16 Wegeberg A-ML, Meldgaard T, Hyldahl S, et al. Physical and psychological health domains of quality of life in type 2 diabetic patients in relation to clinical factors of diabetes mellitus in Egypt. Intern Res J Med Sci 2019;10:87-95.

17 Gredig D, Bartelsen-Raemy A. Diabetes-related stigma affects the quality of life of people living with diabetes mellitus in Switzerland: implications for healthcare providers. Health Soc Care Community 2017;25:1620-33.

18 Chen $\mathrm{H}$. Effect of exercise on the quality of life in type 2 diabetes mellitus: a systematic review. Diabetol Metab Syndr 2017;26:515-30

19 Porojan M, Poantă L, Fodor D. Health-related quality of life of diabetic patients. Rom J Intern Med 2009;47:409-13.

$20 \mathrm{FMOH}$, Ethiopian National Guideline on Major NCDs. Guidelines on clinical and programmatic management of major non communicable diseases. Ministry of Health of Ethiopia, 2016.
21 Reba K, Argaw Z, Walle B, et al. Health related quality of life of patients with diagnosed type 2 diabetes in Felege Hiwot referral Hospital, North West Ethiopia: a cross-sectional study. BMC Res Notes 2018;11:4-9.

22 Ware JE, Sherbourne CD. The mos 36-item short-form health survey (SF-36). Med Care 1992;30:473-83.

23 Cronbach LJ. Coefficient alpha and the internal structure of tests. Psychometrika 1951;16:297-334.

24 Venkataraman K, Wee HL, Leow MKS, et al. Associations between complications and health-related quality of life in individuals with diabetes. Clin Endocrinol 2013;78:865-73.

25 Zheng Y, Ley SH, Hu FB. Global aetiology and epidemiology of type 2 diabetes mellitus and its complications. Nat Rev Endocrinol 2018;14:88-98.

26 Kakhki AD, Abed Z. Health-related quality of life of diabetic patients in Tehran. Int J Endocrinol Metab 2013;11:1-6.

27 Wegeberg A-ML, Meldgaard T, Hyldahl S, et al. Quantities of comorbidities affects physical, but not mental health related quality of life in type 1 diabetes with confirmed polyneuropathy. World $\mathrm{J}$ Diabetes 2019;10:87-95.

28 Daya R, Zbayat FJR. Effects of diabetes mellitus on health-related quality of life at a tertiary hospital in South Africa : A cross-sectional study. Diabetol Metab Syndr 2018;10:918-28.

29 Wändell PE. Quality of life of patients with diabetes mellitus an overview of research in primary health care in the Nordic countries. Diabetol Metab Syndr 2018;10.

30 Muze M, Hailu E, Woldemichael K, et al. Health related quality of life and its associated factors among diabetic patients attending diabetes clinic in Jimma university teaching hospital. Diabetol Metab Syndr 2018;10:7-11.

31 Del Core MA, Ahn J, Wukich DK, et al. Gender differences on SF-36 patient-reported outcomes of diabetic foot disease. Int J Low Extrem Wounds 2018;17:1-7.

32 Gillani SW, Ansari IA, Zaghloul HA, et al. Bridging glycated hemoglobin with quality of life and health state; a randomized case-control study among type 2 diabetes patients. Diabetol Metab Syndr 2018;10:1-10.

33 Qin W, Blanchette JE, Murrock C. Exploring the relationship between lifestyle behaviors and health-related quality of life among older adults with diabetes. Diabetes Educ 2019;45:96-104.

34 Tang TS, Brown MB, Funnell MM, et al. Social support, quality of life, and self-care behaviors among African Americans with type 2 diabetes. Diabetes Educ 2008;34:266-76. 